\title{
O desafio da formação docente
}

\author{
The challenge of teacher education \\ El desafío de la formación del professorado
}

Paula Alexandra Trindade Mota

ORCID: https://orcid.org/0000-0002-6901-6049

Universidade Federal do Maranhão, Brasil

E-mail: pxandrinha19@gmail.com

Tatiara Barbosa

ORCID: https://orcid.org/0000-0003-4589-9366

Universidade Federal do Maranhão, Brasil

E-mail: tatiara.barbosa@discente.ufma.br

Carlos André Sousa Dublante

ORCID: https://orcid.org/0000-0003-3769-1944

Universidade Federal do Maranhão, Brasil

E-mail: carlos.dublante@ufma.br

Dimas dos Reis Ribeiro

ORCID: https://orcid.org/0000-0002-8502-5631

Universidade Federal do Maranhão, Brasil

E-mail: dimas.ribeiro@ufma.br

Francisca Morais da Silveira

ORCID: https://orcid.org/0000-0002-0325-065X

Universidade Federal do Maranhão, Brasil

E-mail: francisca.silveira@ufma.br

Francisco de Assis de Carvalho Almada

ORCID: https://orcid.org/0000-0003-1114-8070

Universidade Federal do Maranhão, Brasil

E-mail: francisco.almada @ufma.br

Ilma Maria de Oliveira Silva

ORCID: https://orcid.org/0000-ooo3-0538-021X

Universidade Federal do Maranhão, Brasil

E-mail: ilmamsilvao@gmail.com

\section{Resumo}

A formação de professores vem sendo objeto de debates e de profundas reformulações no Brasil e no mundo. Neste momento estaremos abordando as questões referentes aos desafios desta formação docente. Trata-se de uma pesquisa realizada com professores de um município do interior do Maranhão que discute os múltiplos desafios da formação docente, abordando os prós e os contras desta profissão. Como fundamentação teórica nos embasamos nos estudos de Miguel Arroyo, Franco, Facci, Morin, Freire, entre outros. A metodologia utilizada foi uma pesquisa bibliográfica e a análise dos dados coletados através de questionário, foram sistematizados de acordo com a Análise de Conteúdo de Bardin. Os estudos sobre a formação docente implicam em um conhecimento das relações que a estruturam, como por exemplo: considerar o professor como sujeito e a escola como espaço de formação; analisar situações do cotidiano da escola; a formação docente envolve um movimento contínuo de desenvolvimento desta profissão. É nesse sentido, que vemos a necessidade de a formação docente ser fortalecida na base.

Palavras-chave: Formação docente; Teoria; Ensino; Práxis.

\begin{abstract}
Teacher education has been the subject of debates and profound reforms in Brazil and around the world. At this moment, we will be addressing the issues related to the challenges of this teacher education. This is a research carried out with teachers from a municipality in the interior of Maranhão that discusses the multiple challenges of teacher education, addressing the pros and cons of this profession. As a theoretical foundation, we are based on studies by Miguel Arroyo, Franco, Facci, Morin, Freire, among others. The methodology used was a bibliographical research and the analysis of the data collected through a questionnaire, were systematized according to the Content Analysis of Bardin. Studies on teacher training imply knowledge of the relationships that structure it, such as: considering the teacher as a subject and the school as a training space; analyze everyday situations at school; teacher training involves a continuous movement towards the development of this profession. It is in this sense that we see the need for teacher training to be strengthened at the base.
\end{abstract}

Keywords: Teacher training; Theory; Teaching; Praxis. 


\begin{abstract}
Resumen
La formación del profesorado ha sido objeto de debates y profundas reformas en Brasil y en todo el mundo. En este momento, estaremos abordando los temas relacionados con los desafíos de esta formación docente. Se trata de una investigación realizada con docentes de un municipio del interior de Maranhão que analiza los múltiples desafíos de la formación docente, abordando los pros y contras de esta profesión. Como fundamento teórico, nos basamos en los estudios de Miguel Arroyo, Franco, Facci, Morin, Freire, entre otros. La metodología utilizada fue una investigación bibliográfica y el análisis de los datos recolectados a través de un cuestionario, fueron sistematizados de acuerdo al Análisis de Contenido de Bardin. Los estudios sobre formación docente implican el conocimiento de las relaciones que la estructuran, tales como: considerar al docente como asignatura y la escuela como espacio de formación; analizar situaciones cotidianas en la escuela; La formación del profesorado implica un movimiento continuo hacia el desarrollo de esta profesión. Es en este sentido que vemos la necesidad de fortalecer la formación del profesorado en la base.
\end{abstract}

Palabras clave: Formación docente; Teoría; Enseñanza; Práctica.

\title{
1. Introdução
}

A Lei de Diretrizes e Bases da Educação (LDB), Lei n ${ }^{\circ}$ 9.394/1996, nos seus artigos 62 e 63, garante a formação de professores para atuação na educação básica, onde destaca que esta dar-se-á em curso de licenciatura, de graduação plena, em universidades e institutos superiores de educação, onde os institutos superiores de educação manterão cursos formadores de profissionais para a educação básica e programas de formação pedagógica para portadores de diplomas de educação superior que queiram se dedicar à educação básica, segundo orientações da nota técnica número 020/2014 do Ministério da Educação (Brasil, 2016). Esta nota introduz um indicador da adequação da formação inicial dos docentes das escolas de educação básica brasileira, seguindo orientações legais.

A Lei no 13.005, de 25 de junho de 2014, que aprova o Plano Nacional de Educação (PNE) na Meta 15, assegura “que todos os professores e as professoras da educação básica possuam formação específica de nível superior, obtida em curso de licenciatura na área de conhecimento em que atuam” (BRASIL, 2017). No entanto, ainda é necessário ir além, e impulsionar políticas públicas que garantam uma formação baseada no trabalho cooperativo, que parta da importância atribuída aos profissionais da educação, sabendo que, o desenvolvimento desses profissionais também segue as trajetórias oriundas das demandas da sociedade.

Com base nestas indagações, delineamos os objetivos de analisar as questões referentes aos desafios da formação docente e dos múltiplos desafios desta formação abordando os prós e os contras desta profissão na voz dos professores. O problema a que esta pesquisa se propõe a responder é: como os docentes enfrentam os múltiplos desafios da sua formação, bem como, compreender os prós e os contras desta profissão.

Este trabalho é relevante ao passo que busca descortinar e ampliar a discussão sobre os desafios da formação docente, bem como perceber os limites e condições dadas aos futuros profissionais para que tenham mecanismos contínuos de desenvolvimento desta profissão, refletindo ainda nestes mecanismos como possibilidades de fortalecimento da de uma educação de qualidade.

\section{Caminhos Metodológicos}

Considerando as particularidades dessa temática, a abordagem da pesquisa é qualitativa, onde segundo Bogdan \& Biklen (1994), o investigador é o instrumento principal, valoriza-se mais o processo do que os resultados ou simples produtos e o significado dos fatos têm importância vital. A investigação se deu por meio de pesquisa bibliográfica e a análise dos dados coletados através de questionário, foram sistematizados conforme a Análise de Conteúdo de Bardin (2011), na tentativa de refletir sobre as questões norteadoras elencadas anteriormente. Utilizamos como fundamentação teórica autores como: Miguel Arroyo (2009), Franco (2012), Facci (2004), Morin (2000), Freire (1996) entre outros. A metodologia utilizada foi uma pesquisa bibliográfica e a análise dos dados coletados através de questionário, foram sistematizados em concordãncia com a Análise de Conteúdo de Bardin (2011). 


\section{Resultados}

\section{a) Saberes necessários à formação docente: teoria $x$ prática}

Refletir sobre a formação docente implica refletir os aspectos que estão contidos no cerne da profissão. Em qualquer nível ou modalidade deve-se considerar como meta o disposto no Art. 22 da LDB 9.394/96, que estipula que “a Educação Básica tem por finalidade desenvolver o educando, assegurar-lhe formação comum indispensável para o exercício da cidadania e fornecer-lhe meios para progredir no trabalho e em estudos posteriores"; esse fim ampara todo e qualquer estudante, para evitar discriminação ou para atender o Art. 61 da mesma LDB, que também é claro a este respeito quando privilegia “a formação de profissionais da educação de modo a atender aos objetivos dos diferentes níveis e modalidades de ensino e as características de cada fase do desenvolvimento do educando".

Assim que as Diretrizes Curriculares Nacionais para a Formação de Professores (DCN) foram promulgadas em 2002, é que se iniciaram as primeiras adaptações nos currículos de formação docente. Partindo daí, foram promulgadas também as diretrizes curriculares para cada curso de licenciatura, aprovadas pelo Conselho Nacional de Educação.

É necessário elencar aqui a obrigatoriedade de nível superior para os professores da educação básica, da LDB (9.394/96), expressa nos artigos 62 e 63 :

Art. 62 - A formação de docentes para atuar na educação básica far-se-á em nível superior, em curso de licenciatura, de graduação plena, em Universidades e institutos superiores de educação, admitida como formação mínima para o exercício do magistério na educação infantil e nas quatro primeiras séries do Ensino Fundamental, a oferecida em nível médio, na modalidade Normal.

Art. 63 - Os Institutos Superiores de Educação manterão:

I - Cursos formadores de profissionais para a educação básica, inclusive o curso normal superior, destinado à formação de docentes para a educação infantil e para as primeiras séries do Ensino Fundamental;

II - Programas de formação pedagógica para portadores de diplomas de Educação Superior que queiram se dedicar à educação básica;

III - Programas de educação continuada para profissionais de educação dos diversos níveis.

A Formação de Professores da Educação Básica foi instituída em 2002 pelas Diretrizes Curriculares Nacionais, com a preocupação maior no desenvolvimento de competências pessoais, sociais e profissionais dos docentes. As orientações foram elaboradas para os docentes que atuarão no ensino básico, em diferentes níveis. Foi indicado que a capacitação deste docente, seja para o exercício profissional específico devendo considerar, o desenvolvimento de competências necessárias à atuação, bem como, dando ênfase a formação oferecida e à prática deste futuro profissional da educação e, de outro, a pesquisa, dando ênfase ao ensino e a aprendizagem, para a construção do conhecimento. Propondo ainda que as aprendizagens sejam orientadas pelo princípio da ação - reflexão - ação, considerando a reflexão sobre situações-problema como uma das estratégias didáticas privilegiadas. No artigo $6^{\circ}$, reafirmou a importância da cultura geral e profissional, conhecimento pedagógico e conhecimento advindo da experiência (Brasil, 2002).

Segundo Imbernón (2011), no contexto atual da educação, não é mais admissível que se pratique técnicas tradicionais no ambiente educacional, o docente precisa mais que apenas transmitir os conhecimentos, bem como, não deve mais ensinar apenas o básico e reproduzindo conteúdos com objetivo de dominar o aluno. O autor frisa ainda que nesta profissão é importante que o docente acompanhe a evolução dos seres humanos.

Para Libâneo (2016, p. 252), "o professor estabelece objetivos sociais e pedagógicos, seleciona e organiza os conteúdos, escolhe métodos, organiza a classe". Esse autor, vê o professor como "mediador e incentivador" da aprendizagem entre cada aluno e os modelos de conteúdos culturais. É imprescindível que ele esteja sempre motivado para ensinar e seja um incentivador na construção deste saber. 
A inter-relação entre teoria e prática é um dos maiores empecilhos do desenvolvimento docente no país, do qual as novas diretrizes tentam lidar, a grande maioria desses futuros profissionais saem da universidade dominando os conteúdos, porém com pouco embasamento didático. Ao se deparar com ambiente educativo, o professor, sente-se completamente perdido porque não sabe como passar aquele conteúdo que viu na Universidade, ou seja, durante o processo de graduação.

Para Franco (2012), é importante levar em consideração também que o desenvolvimento docente não acontece no espaço vazio, deve estar sempre vinculada a uma intencionalidade, a uma política, a uma epistemologia a pesquisas. Sabendo que, a formação de professores deve sempre ser vinculada a um projeto político, pois sem essa associação, só pode caracterizar uma concepção extremamente pragmatista, reprodutivista, tecnicista da ação docente.

Em se tratando da formação docente a situação necessita de uma postura que vá além de pequenos ajustes. O ideal seria que pudéssemos revolucionar a formação docente. Levando em consideração que os cursos universitários que licenciam os futuros profissionais não possuem estrutura adequada para formar um professor, elas ainda necessitam de ajustes no conhecimento teórico e nas técnicas de ensino necessárias para uma boa atuação nas instituições de ensino. Alguns cursos de licenciaturas estão formando geógrafos, biólogos e matemáticos, mas não docentes de geografia, biologia e matemática.

Nos cursos atuais de formação de professor, ou se dá grande ênfase à transposição didática dos conteúdos, sem sua necessária ampliação e solidificação - "pedagogismo", ou se dá atenção exclusiva a conhecimentos que o estudante deve aprender - "conteudismo", sem considerar sua relevância e sua relação com os conteúdos que ele deverá ensinar na educação básica (Brasil, 2000, p. 26).

A ausência de sincronia durante a formação com o chão real da escola é outro fator visto como um conjunto de obstáculos para os professores recém-formados que acabaram de ingressar nas instituições de ensino. No decorrer desse processo de formação, o desenvolvimento de algumas competências e habilidades necessárias para a prática docente acabam não sendo valorizadas, o que fará falta na sua atuação em sala de aula. E o que também nos leva a indagar se as universidades, de modo geral, estão mais preocupadas com a formação de pesquisadores e não de professores.

A formação inicial, na Universidade, precisa preparar o docente, no intuito de que ele seja capaz de compreender a realidade em que seu aluno está inserido, ter o domínio dos conteúdos e saber ensinar, além de ser empático com as famílias da comunidade, entendendo o contexto no qual está inserido e qual seu papel. É importante refletir que os currículos dos cursos de pedagogia ou licenciaturas necessitam ser reformulados, no entanto, necessariamente a postura dos docentes formadores das Instituições de graduação também precisa mudar.

No interior da universidade, existe uma pedagogia, que necessita ser reelaborada e atualizada, existem formadores muito tradicionais, acreditando que ainda é possível ensinar dentro dos moldes nos quais aprenderam, no entanto, é imprescindível que futuro professor crie referências, neste sentido, é necessário aplicar no decorrer da sua formação as mesmas práticas pedagógicas que deverão utilizar com seus alunos em sua atuação na escola.

É importante ressaltar que, com o avanço tecnológico planetário e o acesso cada vez mais cedo, das crianças e adolescentes a essa tecnologia, de certa forma, esse aluno vai reivindicar por uma interação maior no ambiente educativo desse docente frente a essas demandas. É necessário que os futuros profissionais da educação estejam preparados para atuarem neste contexto, onde possam intervir como mediadores do saber, promovendo a inclusão de todos os alunos. Nóvoa (1995, p. 25), diz que "a formação do professor não se constrói por acumulação (de cursos, de conhecimentos, de técnicas), mas sim por meio de um trabalho de reflexibilidade crítica sobre as práticas e de (re)construção permanente de uma identidade pessoal" (apud Facci, 2004, p. 41).

As novas linguagens tecnológicas educacionais também devem estar incorporadas no desafio de formar novos professores. É imprescindível que o professor esteja preparado para empregar na sua rotina, em sala de aula ou fora dela, todos 
os recursos que oferecerão uma aprendizagem diferenciada para os alunos. Perante o exposto, todas essas exigências, frente a formação dos professores e levando em consideração competências e habilidades que devem ser adquiridas, como podemos saber se os novos professores recém-formados estão aptos para lidar com a realidade no ambiente educacional de ensino?

A avaliação deste processo de formação docente também é algo desafiador para o país. A maior preocupação é criar estratégias de acompanhamento que não simbolizem qualquer forma de castigo ou punição, mas deem conta de mensurar os futuros profissionais e oferecer auxílio para o desenvolvimento da sua prática. A responsabilidade de aprimorar e formar pessoas é muito grande, é necessário que os responsáveis por essa formação estejam constantemente atualizados de acordo com uma didática alinhada para o século 21.

\section{b) O educador e sua formação no contexto atual}

O docente tem uma função importantíssima na vida do aluno. A deliberação, ou seja, a decisão sobre como será a formação dos formadores acaba gerando um impacto no projeto educacional da sociedade. As mudanças nas formas de aprender e ensinar são constantes, e os cursos de licenciatura devem estar preparados para dialogarem com as novas possibilidades da sala de aula, preparando os futuros professores para atuarem como mediadores de aprendizagem.

Morin (2000), em Os Sete Saberes, diz que a educação resulta da combinação de diferentes saberes, visto que, o que existe hoje é a fragmentação da educação, onde percebemos duas linhas: de um lado a escola, dividida em partes, de outro lado a vida, onde os problemas são multidisciplinares, globais e planetários. O autor afirma ainda que a falta do conhecimento decorre da educação recebida, ou seja, da falta dessa educação.

O Plano Nacional de Educação (PNE) destina quatro de suas 20 metas aos professores: prevê formação inicial, formação continuada, valorização do profissional e plano de carreira. O Brasil tem 1,4 milhão de docentes em atividade nas salas de aula da educação básica, de acordo com o Censo Escolar da Educação Básica 2019, realizado pelo Instituto Nacional de Estudos e Pesquisas Educacionais Anísio Teixeira (Inep).

A atual conjuntura contrapõe com a meta número 15 do PNE, a qual preconiza que todos os professores da educação básica tenham formação específica de nível superior, obtida em curso de licenciatura na área em que atuam. A formação inicial dos professores no Brasil ainda é muito frágil. É uma formação insatisfatória em relação aos requisitos estabelecidos nas próprias leis brasileiras. É importante priorizar o PNE para que nos aproximemos das metas.

Uma das medidas adotadas logo após o primeiro ano de vigência do PNE, em julho de 2015, foram as novas diretrizes para a formação de professores, elaboradas pelo CNE (Conselho Nacional de Educação). Este documento preconiza o aumento do tempo mínimo de formação para os cursos de licenciatura, que passaram de 2.800 para 3.200 horas. Além do aumento dessas horas, os cursos também deverão contar com mais atividades práticas, levando os futuros profissionais do ensino a vivenciarem o cotidiano da escola.

A aprendizagem de competências tem um caráter definitivo quando relacionam o conteúdo com as vivências dos alunos, quando se reconhece o chão que o aluno pisa, essas experiências quando valorizadas transforma-os em agentes ativos no seu próprio aprendizado ao expor seus anseios e necessidades. Constrói-se assim, um processo de ensinar e de aprender por meio do diálogo que, para Freire (1994, p. 120), "Enquanto relação democrática, o diálogo é a possibilidade de que disponho de, abrindome ao pensar dos outros, não fenecer no isolamento."

Ao se deparar com a particularidade do ambiente educativo, o professor percebe que esta não cabe em um conceito, é necessário construir certo distanciamento teórico, sempre levando em consideração a importância da teoria para o desenvolvimento da prática na sua atuação. O comportamento dos professores no desenvolvimento de suas atividades com os alunos causa impactos significativos na aprendizagem e na vida. 
Freire (1996, p.17) questiona: "por que não estabelecer uma necessária 'intimidade' entre os saberes curriculares fundamentais aos alunos e a experiência social que eles têm como indivíduos?” Respeitar os diferentes olhares da realidade social que os alunos têm deve ser o primeiro passo para uma educação transformadora. É muito mais complicado mediar as aprendizagens dos alunos sem antes conhecê-los para, a partir daí, construir novas simbologias da realidade.

É preciso atribuir um novo valor às técnicas e metodologias escolares e, para isso, o professor precisa ser capacitado para encarar os desafios de frente da escola contemporânea. Segundo a Proposta de Diretrizes para a Formação Inicial de Professores, na graduação

As mudanças propostas para a Educação Básica no Brasil trazem enormes desafios à formação de professores. No mundo contemporâneo, o papel do professor está sendo questionado e redefinido de diversas maneiras. Para isso concorrem as novas concepções sobre a educação, as revisões e atualizações nas teorias de desenvolvimento e aprendizagem, o impacto da tecnologia da informação e das comunicaç̃̃es sobre os processos de ensino e de aprendizagem, suas metodologias, técnicas e materiais de apoio. Tudo isso delineia um cenário educacional com exigências para cujo atendimento os professores não foram, nem estão sendo preparados (Brasil, 2000, p.5).

O professor deve estar em constante formação para que possa aprimorar suas práticas pedagógicas no ambiente educativo, e receber suporte em seu desenvolvimento profissional. A formação continuada pode acontecer por meio de cursos, troca entre os pares ou até mesmo atividades elaboradas nas escolas no intuito de atualizar conhecimentos, desenvolver novas habilidades e competências, aprofundar conceitos e técnicas referentes a alguns temas específicos, além de construir sua identidade.

Para Pimenta (2007, p.20), a identidade do docente se constrói a partir do significado social dado pelo próprio docente e da sociedade em geral, levando em consideração todo o contexto de tradições. "Mas também da reafirmação de práticas consagradas culturalmente e que permanecem significativas. Práticas que resistem a Inovações porque prenhes de saberes válidos às necessidades da realidade".

Para a Formação Inicial e Continuada dos Profissionais do Magistério da Educação Básica, de acordo com as Diretrizes Curriculares Nacionais (2015), é necessário que o professor consiga “dominar os conteúdos específicos e pedagógicos e as abordagens teórico metodológicas do seu ensino, de forma interdisciplinar e adequada às diferentes fases do desenvolvimento humano" (Brasil, 2015, p. 26).

Freire (1996, p. 22) afirma que, "a prática docente crítica, [...] envolve o movimento dinâmico, dialético, entre o fazer e o pensar sobre o fazer" O professor deve repensar sua prática, levando em consideração que somente uma prática docente crítica pode proporcionar mudanças no seu fazer pedagógico para a educação que visa a uma aprendizagem significativa para o aprendente.

Ainda segundo Freire (1996, p. 22) "É por isso que, na formação permanente dos professores, o momento fundamental é o da reflexão sobre a prática. É pensando criticamente a prática de hoje ou de ontem que se pode melhorar a próxima prática". E, para que seja possível melhorar a prática, é necessário buscar novos conhecimentos para a multiplicação de possibilidades e melhoria da atuação.

\section{Discussão}

Considerando os aspectos relacionados à formação docente, consoante os órgãos governamentais e as instituições que fomentam essa estrutura educacional, é importante analisar a efetividade do Plano Nacional de Educação junto aos professores que são os principais beneficiados nesse contexto. 
Para isso, na cidade de Imperatriz/MA foi realizada pesquisa envolvendo alguns segmentos educacionais, sobretudo da ensino básico, entre os dias 26 e 30 de abril de 2021; mediante formulário do Google Forms, 13 professores responderam a cinco questões relacionadas à licenciatura/graduação e atuação docente dos últimos anos.

Embora aparentemente ínfima essa quantidade, ante a amplitude dos profissionais de ensino, as respostas refletem a realidade de um grande número de docentes, fato observado nas resoluções. E que serão discutidas no decorrer das respostas.

\section{a) Perfil de formação dos entrevistados}

Em se tratando da formação dos entrevistados 50\% são graduados em pedagogia e os outros 50\% são graduados em outras áreas de formação. Os professores entrevistados atuam no ensino básico, numa média entre 6 e 30 anos de atuação, estando os mesmos vinculados da educação infantil ao ensino médio.

A inserção na carreira docente aconteceu por diferentes motivos citados pelos entrevistados no questionário. Dentre eles, estão o amor pela profissão, estabilidade, incentivo da família, e por mais complexo que possa parecer tivemos respostas como a falta de outras possibilidades de graduação e fácil acesso à carreira docente. Pontuação que nos leva a refletir, seria esse tipo de professor, o professor que desqualifica a profissão? O que escolhe a profissão docente por falta de outros cursos de graduação?

Esse processo de escolha da profissão é importantíssimo para que, neste caso específico, o docente tenha identidade profissional. Como ter o reconhecimento social sem "EU" mesmo como profissional não me reconheço como profissional da educação. Arroyo (2009, p.28) cita que "profissionalizados seremos capazes de separar nossos tempos, tirar a máscara após cada dia de docência e mostrar nossos múltiplos rostos com orgulho".

Silva e Nunes (2020) afirmam que a formação docente é uma questão muito complexa, chegando a ser problemática no contexto educacional da sociedade, sabendo que existem uma série de fatores sociais, políticos, econômicos, psicossociais e pessoais, entre outros, que refletem nas práticas pedagógicas e na qualidade da educação.

\section{b) Prós e contras da formação docente}

Mariano (2006, p.19) afirma que nós professores, "sonhamos com a estreia! Vivemos uma grande expectativa e somos tomados por uma grande ansiedade antes de subirmos ao palco pela primeira vez. Achamos que vamos encontrar cada parte do cenário no lugar exato dos nossos sonhos...." O que nos faz criar expectativas sobre todo o processo de ensinar.

Ao analisar os prós e os contras da formação docente na voz dos professores percebemos falas de amor, gratidão e muito aprendizado no decorrer da experiência com a docência. Bem como, também desvalorização e pouca expectativa de mudança.

O docente A, cita que "É gratificante ver o processo de aprendizagem acontecer, perceber que o aprendizado é colocado em prática no dia a dia". Freire (2005) enfatiza que ambos, professores e alunos, são transformados no processo da ação educativa e aprendem ao mesmo tempo em que ensinam, sendo que o reconhecimento dos contextos e histórias de vida neste diálogo se desdobra em ação emancipadora.

O Docente $\mathbf{C}$, cita que "A cada ano novas adaptações tecnológicas formam prós e contras no processo de ensino aprendizagem". A cada ano, um novo desafio é traçado com metas a serem cumpridas, neste momento de pandemia do covid19, os professores de reafirmaram como profissionais, se refizeram como docentes, se reinventaram mediante o ensino remoto proposto aos alunos e mostraram sua habilidade de se reconstruir.

Miguel Arroyo (2009) vem afirmando que

As políticas de formação e de currículo e, sobretudo, a imagem de professor(a) em que se justificam perderem essa referência ao passado, à memória, à história, como se o professor(a) fosse um cata-vento que gira à mercê da última vontade política e da última demanda tecnológica. A cada nova ideologia nova moda Econômica ou política pedagógica 
e acadêmica cada novo governante gestor ou tecnocrata até de agências de financiamento se julgam no direito de nos dizer o que nós somos e o que devemos ser de definir nosso perfil de redefinir nosso papel social nossos saberes e competências redefinir o currículo e a instituição que nos formaram através de um simples decreto (p. 24).

O docente $\mathbf{D}$, cita que a "desvalorização social e salarial, o acúmulo de funções, a falta de incentivos é uma vivência da profissão. Facci (2004) afirma que é uma vivência real, a problemática perpassa a crise de identidade vivida pelo professor, ela está literalmente relacionada aos status que a própria profissão ocupa no nível social estabelecido pela sociedade. Bem como a precariedade da formação deste profissional, o investimento que não é realizado na formação e a desvalorização por parte dos governantes que não elaboram políticas públicas para educação de qualidade e nem é disponibilizado recursos financeiros.

Docente F, coloca que os contras da profissão docente: Desvalorização por parte de alunos, pais e pouco incentivo financeiro. Sobre esse tema Miguel Arroyo (2016, p. 46) afirma que "Essas condutas chocantes em crianças são a fase cruel da globalização que com tanto ardor criticamos. [...] Reproduzem na escola os valores que são obrigados a viver para sobreviver nas ruas, na família, na cidade e nos campos".

O docente $\mathbf{H}$, afirma em sua fala que "A beleza da profissão, a satisfação em poder contribuir pra uma sociedade melhor são os prós da profissão docente". Analisando a resposta do professor em questão, percebemos que, o trabalho docente traz sentimentos de realização muito significativos, os quais ficam evidentes quando o objetivo de aprendizagem é alcançado e quando o reconhecimento de alunos e pais acontece durante o processo. Knüppe (2006), a respeito disso constatou haver ligação entre a expectativa e receptividade dos alunos e a motivação dos professores.

O Docente I, relata que "a falta de reconhecimento é um dos contras da profissionalização docente". Para esse tema, Arroyo (2009, p.29) afirma que "O discurso do profissionalismo é um sonho ambíguo. Do lado da categoria pode significar reconhecimento e valorização. Do lado social, pode significar a justificativa para adiar esse reconhecimento". A docência está longe de ser um sacerdócio, porém, não há como desempenhar essa função sem convicção, mesmo estando ciente de seus obstáculos. Freire (1996) afirma que ensinar exige segurança, competência profissional e generosidade. Generosidade no ensinar, partilhar e no aprender.

\section{Considerações Finais}

Refletir acerca da formação docente é um processo necessário, principalmente no que tange a formação inicial, este é um assunto que ainda merece ser discutido dentro e fora das universidades, uma vez que as mudanças ainda são bastante tímidas.

Há ainda muito a ser feito em relação a formação de professores, no entanto temos muitos docentes que pensam a educação não como uma simples reprodução do conhecimento, mas, como meio de transformações sociais e formação de cidadãos capazes de mudar sua realidade.

A partir do que foi exposto no artigo consideramos fundamental pensar em estratégias formativas que considerem tal problemática, auxiliando na minimização dos efeitos negativos que o docente iniciante enfrenta ao se deparar com a realidade do ambiente escolar, com o chão que pisa o aluno.

Desta forma, o estudo realizado a respeito da formação de professores, conclui-se que é imprescindível uma reviravolta nos currículos da formação, com vistas a possibilitar ao futuro professor uma formação mais sólida, reflexiva e condizente com a realidade da escola.

Assim, considerando que o desafio da formação docente é o calcanhar de aquiles da Educação, compreendemos a necessidade de desenvolver futuros trabalhos que possam aprofundar os estudos no âmbito da capacitação dos professores apontando a importância da inserção das políticas públicas voltadas à educação de qualidade na escola. 


\section{Referências}

Arroyo, M., G, (2016). Imagens quebradas: trajetória e tempos de alunos e mestres. (8a ed.), Vozes.

Arroyo, M., G (2009). Ofício de mestre: Imagens e auto-imagens. (10a ed.), Vozes.

Brasil. (1996). Lei n 9.394 de 20 de dezembro de 1996. Estabelece as Diretrizes e Bases da Educação. http://www.planato.gov.br.

Brasil (2014). Lei no 13.005, de 25 de junho de 2014. Aprova o Plano Nacional de Educação - PNE e dá outras providências. Publicado na Edição Extra do Diário Oficial da União, de 26 de junho de 2014, nº 120-A. http://www.planalto.gov.br/ccivil_03/_ato2011-2014/2014/lei/113005.htm.

Brasil (2002). MEC. Resolução CNE/CP 1, de 18 de fevereiro de 2002. Institui Diretrizes Curriculares Nacionais para a Formação de Professores da Educação Básica, em nível superior, curso de licenciatura, de graduação plena. http://portal.mec.gov.br/cne/arquivos/pdf/rcp01_02.pdf.

Brasil (2000). Ministério da Educação. Proposta de diretrizes para a formação inicial de professores da educação básica em curso de nível superior. Brasília, 2000. http://portal.mec.gov.br/cne/arquivos/pdf/basica.pdf.

Brasil (2015). Ministério da Educação. Conselho Nacional de Educação. Parecer CNE/CP n 2/2015. Diretrizes Curriculares Nacionais para a Formação Inicial e Continuada dos Profissionais do Magistério da Educação Básica. Brasília, 2015. http://portal.mec.gov.br/index.php?option=com_docman\&view=dow nload\&alias=136731-rcp002-15-1\&category_slug=dezembro-2019-pdf\&Itemid=30192.

Brasil (2020). Instituto Nacional de Estudos e Pesquisas Educacionais Anísio Teixeira (Inep). Censo da Educação Básica 2019: resumo técnico. Brasília.

Facci, M. G. D. (2004). Valorização ou esvaziamento do trabalho do professor? Um estudo crítico-comparativo da teoria do professor reflexivo, do construtivismo e da psicologia vigotskiana. Campinas: Autores Associados.

Franco, M. A. R. S. (2012). Pedagogia e prática docente. Editora Cortez.

Freire, P. (1994). Pedagogia da esperança: Um reencontro com a Pedagogia do oprimido. Paz e Terra.

Freire, P. (1996). Pedagogia da Autonomia: saberes necessários à prática educativa. (25a ed.), Paz e Terra.

Freire, P. (2005). Pedagogia do Oprimido. Editora Paz e Terra.

Imbernón, F. (2011). Formação docente e profissional: formar-se a mudança e a incerteza. Tradução: Silvana Cobucci Leite. (9a ed.), Cortez.

Knuppe, L. (2006). Motivação e desmotivação: desafio para as professoras do ensino fundamental. Educar, (27), 277-290

Libâneo, J. C. (2017). Didática. Cortez.

Mariano, A. L. S. (2006). O início da docência e o espetáculo da vida na escola: abremse as cortinas... In: LIMA, Emília Freitas de. Sobrevivências no início da docência. Brasília: Líber Livro Editora.

Morin, E. (2000). Os Sete Saberes Necessários à Educação do Futuro. (2a ed.), Editora Cortez, 118p.

Pimenta, S. G. (2007). (Org.) Saberes pedagógicos e atividade docente. Cortez.

Silva, J. M. N. \& Nunes, V. G. C. (2020). Formação continuada docente: uma análise a partir da Lei de Diretrizes e Bases da Educação Nacional (LDB/1996) e das Diretrizes Curriculares Nacionais para a Formação Inicial e Continuada de Professores da Educação Básica (Resolução CNE-CP 2/2015). Research, Society and Development, 9(8), 353985150 . 